\title{
The impact of tobacco control policies on smoking initiation in eleven European countries
}

\author{
Ali Palali ${ }^{1} \cdot$ Jan C. van Ours ${ }^{2,3,4,5}$ \\ Received: 9 October 2018 / Accepted: 31 July 2019 / Published online: 9 August 2019 \\ (c) The Author(s) 2019
}

\begin{abstract}
We investigate the effect of tobacco control policies on smoking initiation in eleven European countries. Based on individual data about age of onset of smoking, we use hazard rate models to study smoking initiation. Thus, we are able to take into account observed and unobserved personal characteristics as well as the effect of the introduction of a variety of tobacco control policies including price and and non-price policies, i.e., bans on tobacco advertisements, smoke-free air regulation, health warnings on packages of cigarettes, and treatment programs to help smokers quit smoking. We find that higher tobacco prices have a negative effect on the initiation into smoking for males but not for females. We find no effect of non-price tobacco control policies on smoking initiation.
\end{abstract}

Keywords Tobacco control policies $\cdot$ Smoking initiation $\cdot$ Hazard rate models

JEL Classification I12 $\cdot$ C41

\section{Introduction}

According to the World Health Organization tobacco use is an epidemic. In the past decades, a large amount of evidence has piled up about the adverse health consequences of tobacco use [24]. These health effects have recently reached an alarming peak, which makes tobacco use one of the biggest health threats ever, killing approximately one person every $6 \mathrm{~s}$ [29]. Nearly, 6 million people die every

Electronic supplementary material The online version of this article (https://doi.org/10.1007/s10198-019-01090-x) contains supplementary material, which is available to authorized users.

Jan C. van Ours

vanours@ese.eur.nl

Ali Palali

ali.palali@booking.com

1 Booking.com, Amsterdam, The Netherlands

2 Erasmus School of Economics, Erasmus University Rotterdam, Rotterdam, The Netherlands

3 Department of Economics, University of Melbourne, Parkville, Australia

4 Tinbergen Institute, Rotterdam, The Netherlands

5 CEPR, London, UK year because of tobacco-related diseases, a number which is expected to reach 8 million by 2030 .

The gloomy health effects have stimulated many governments to introduce tobacco control policies. First and foremost, smoking is discouraged by imposing substantial taxes on tobacco products thus increasing prices. Furthermore, there are non-price tobacco control policies ranging from prohibition or restriction of advertisements of tobacco products to laws necessitating the placement of health warnings on tobacco product packages and from different types of anti-smoking campaigns to laws prohibiting the use of tobacco in certain places. Nearly, one-third of the world's population is covered by at least one type of comprehensive non-price tobacco control policy and a considerable amount of resources is spent to enforce these policies [46].

To what extent tobacco control policies actually affect smoking is an empirical question. Past research on the effects of tobacco control policies is not conclusive. Whereas tobacco prices, bans on cigarette advertisements and placement of health warnings on tobacco and cigarette packages seem to have had a negative effect on the number of smokers and the per capita cigarette consumption, this is less clear for smoking bans, i.e., restrictions on smoking in public places and workplaces. Some studies find a negative effect on smoking, while others find no effect. 
Most studies focus on the extensive or intensive margin of smoking, i.e., on the share of smokers in a population or the tobacco consumption per smoker. From a policy point of view, it is also important to assess the effects of tobacco control policies on smoking initiation. Early initiation has important effects later on in life. Van Ours [43] shows that the age of onset of tobacco use is an important predictor of life-time tobacco use. An individual who starts smoking at an early age has a higher probability of longterm tobacco use compared to someone who starts later. Sharapova et al. [41] find that earlier ages of tobacco use initiation among US middle and high school students are associated with sustained tobacco use and greater nicotine dependence. The authors conclude from this that the reinforcement of comprehensive efforts to reduce tobacco use initiation among youth is important to reduce overall youth tobacco use. Since the age of onset is a very strong predictor of addiction and quit behavior, analyzing the effects on smoking initiation is important not only for early smoking behavior, but also for smoking dynamics in general. Early ages of onset imply a greater probability of persistent smoking later on in life with serious health consequences. Pirie et al. [38], for example, show smoking to have a big effect on mortality rates of UK women. Of the female smokers, $53 \%$ died before age 80 years, while for never-smokers, this was $22 \%$. There appeared to be a lifespan difference between smokers and non-smokers of 11 years. Pirie et al. [38] also find that stopping to smoke before age 40 years avoids more than $90 \%$ of the excess mortality. This also implies that early age of onset of smoking may have a big impact on mortality rates. The implicit assumption behind policies targeting youth's smoking is that reducing smoking initiation at a young age reduces lifetime smoking propensities [19] and thus has positive health effects.

We analyze Eurobarometer data from Austria, Germany, Finland, France, Ireland, Italy, The Netherlands, Portugal, Spain, Sweden, and United Kingdom to study the effects of tobacco control policies on smoking initiation. We consider the effect of tobacco prices but also study the effects of non-price tobacco control policies in particular smoke-free air laws, bans on advertising promotion and sponsorship, health warnings on tobacco product packaging and treatment programs to help dependent smokers to stop smoking. The eleven European countries differ in the timing of introduction of the various tobacco control policies. To analyze the effects of these policies on smoking initiation, we use mixed proportional hazard rate models, which control for observed as well as unobserved determinants of smoking initiation.

Our study has three contributions to the literature on the effects of tobacco control policies. First, we contribute to the small literature about the effects of tobacco control policies on smoking initiation. Second, we present one of the first studies using individual level cross-country data, capturing the variation in the implementation of various tobacco control policies in European countries. The cross-country variation enables us to study the causal effects of tobacco control policies in an international context. Third, we use hazard rate models in our empirical analysis. The dynamics in smoking behavior are rather complex. Individuals start smoking over only a limited age range. If they have not started smoking by their early twenties, they are very unlikely to start smoking later on. Using a hazard rate framework allows us to take these peculiarities into account.

The setup for the remainder of our paper is as follows. In "Previous studies", we provide an overview of the previous empirical studies on the impact of tobacco control policies. We distinguish between studies focusing on the extensive and intensive margin of smoking and studies focusing on smoking dynamics. "A simple model of smoking initiation" provides a simple theoretical model to explain how tobacco control policies may affect smoking initiation. "Smoking in Europe" presents information about tobacco control policies in Europe and discusses the data we use in the empirical analysis. These are from one survey, where we introduce a time dimension using information on the age of onset. "Empirical analysis" presents the setup of our analysis and our parameter estimates. In recent decades smoking of females has increased a lot, such that in some countries, smoking prevalence of females is not very different from the smoking prevalence of males. Nevertheless, in most countries, there is still a clear gender difference in smoking prevalence. Therefore, we do the analysis separately for females and males. Our main findings are that high tobacco prices reduce the onset of smoking for males, but not for females, while non-price tobacco control policies do not influence smoking initiation. Conclusions concludes.

\section{Previous studies}

Tobacco advertisements aim to persuade youngsters to start smoking, encourage current smokers to keep smoking, and stimulate past smokers to restart smoking. They also aim to increase amounts of cigarettes smoked [45]. Cigarette advertisements can influence public discussions about negative consequences of smoking causing people to think that negative effects are overrated [9]. In short, tobacco advertisements encourage smoking and thus bans on these advertisements aim to remove this encouragement. Bans on advertisements are an important component of tobacco control policies. Early studies on the relationship between tobacco control policies and smoking are based on aggregate data using cross-country time series variation. Saffer and Chaloupka [40], for example, analyze the effects of banning tobacco advertisements on per capita cigarette consumption in 22 OECD countries over the period 1970-1992. They find 
that comprehensive laws prohibiting advertisements have strong effects on per capita cigarette consumption, whereas non-comprehensive laws have limited effects. Blecher [4] analyzes the effects of laws prohibiting cigarette advertisements in 52 countries worldwide over the period 1990-2005 finding that both comprehensive bans and limited bans have a significant negative impact on per capita cigarette consumption.

Other tobacco control policies are the placement of health warnings on tobacco and cigarette packages and general campaigns about the negative health consequences of smoking. Health warnings can affect smoking both at the intensive and the extensive margin, i.e., the number of cigarettes per smoker and the share of smokers in the population. Warnings convey direct information about adverse health effects of smoking. This may prevent young individuals from starting to smoke. Moreover, health warnings on cigarette packages may reduce the intensity of smoking or stimulate quitting from smoking.

Restrictions on smoking in public places or workplaces can directly affect cigarette consumption by making it harder for people to smoke. Moreover, such restrictions can easily affect the perception of smoking. First, these restrictions might work as a reminder of the negative consequences of smoking, especially for young individuals. Second, young individuals are less likely to be exposed to passive smoking thanks to these restrictions. The absence of smokers can affect their perception of cigarette consumption, i.e., when youngsters are less often exposed to smokers they may experience this as confirmation of negative health consequences of smoking.

In Table 1, we present a summary overview of studies that are mostly based on individual data. The effects of tobacco prices and tobacco control policies are usually based on calendar time variation, cross-state or cross-region variation or a combination of both. We distinguish between studies that focus on prevalence and intensity of smoking and studies that focus on smoking dynamics, i.e., smoking initiation and quitting.

\section{Prevalence and intensity of smoking}

Chaloupka and Grossman [8] state that anti-smoking campaigns have had significant negative effects on youth smoking at both the intensive and the extensive margin. Using US data Meier and Licari [31] analyze the effects of health warnings on smoking along with the effects of taxes. They find that health warnings on cigarette packages have small but significant negative effects on cigarette consumption. Chaloupka and Wechsler [10] find that in the US, smoking restrictions have negative effects on smoking at both the intensive margin and the extensive margin. They also find that age restrictions on the access to tobacco seem to have had little impact as the effectiveness of such laws depends on their enforcement. Powell et al. [39] investigating smoking behavior of US high school students find that both cigarette prices and state-level and school-level tobacco control policies have a negative effect on tobacco use. These negative effects are reinforced through the existence of peer effects. Adda and Cornaglia [2] find that laws prohibiting smoking at workplaces do not have any effect on smoking prevalence or per capita cigarette consumption. However, they find that smoking bans in bars and restaurants have small but significant negative effects. Nagelhout et al. [33] find that the workplace smoking ban introduced in The Netherlands in 2004 decreased smoking prevalence, while the smoking ban in bars and restaurant introduced in 2008 did not have an effect. Anger et al.'s [3] study the effects of smoking bans who were gradually introduced in all of Germany's federal states. Using a difference-in-differences approach, they find that the smoke-free legislation on average did not affect smoking behavior. However, among visitors of bars and restaurants, smoking and smoking intensity were reduced. Smoke-free legislation is primary aimed to protect non-smokers from the harm of second-hand smoking. However, this legislation may also induce smokers to quit smoking. ${ }^{1}$

Smoke-free legislation is not necessarily beneficial for non-smokers. Possibly, smoking bans in public places lead to more smoking at home. Jones et al.'s [21] study the effects of public smoking bans on smoking behavior exploiting the differential timing of the introduction of these bans in Scotland and England finding that they had limited short-run effects on both smoking prevalence and the total level of smoking. Boes et al.'s [5] study the effect of a Swiss smoking ban in public venues. Because these bans were introduced in different regions at different moments in time, they are able to use a difference-in-differences approach finding a negative effect on smoking rates 1 year after the implementation of the bans. Villar and Nicolás [44] analyze the effects of the Spanish clean air law finding a reduction in the proportion of households containing smokers. In a recent study, Cotti et al. [11] investigate the impacts of tobacco control policies finding that an increase in the tobacco taxes significantly reduced the tobacco consumption and increased the consumption of smoking cessation products. However, they also find that a smoke-free-air policy banning smoking in bars do not have any significant effects on the consumption of tobacco products. DelBono and Vuri [15] provide an overview of European studies on the effects of smoking

\footnotetext{
${ }^{1}$ Nagelhout et al. [32] find mixed evidence for this. In England and Ireland smoke-free legislation may have stimulated quits from smoking, while in The Netherlands, this does not seemed to have been the case.
} 
Table 1 Overview of the previous studies on tobacco control policies

\begin{tabular}{|c|c|c|c|c|c|c|}
\hline Study & Data & & Time & Dependent variable & TCP & Effects \\
\hline \multicolumn{7}{|c|}{ a. Prevalence and intensity of smoking } \\
\hline Chaloupka and Grossman [8] & I & US & 1992-1994 & Youth smoking & Anti-smoking campaigns & Negative \\
\hline Meier and Licari [31] & $S$ & US & $1955-1994$ & Cigarette consumption & Health warnings & Negative \\
\hline Chaloupka and Wechsler [10] & I & US & 1993-1996 & Youth smoking & Smoking restrictions & Negative \\
\hline Powell et al. [39] & I & US & 1996 & Tobacco use & $\begin{array}{l}\text { Various TCP } \\
\text { Tobacco prices }\end{array}$ & $\begin{array}{l}\text { Negative } \\
\text { Negative }\end{array}$ \\
\hline Adda and Cornaglia [2] & $\mathrm{S}$ & US & $1970-2007$ & Per capita consumption & $\begin{array}{l}\text { Various smoking bans } \\
\text { Cigarette prices }\end{array}$ & $\begin{array}{l}\text { Mixed } \\
\text { Negative }\end{array}$ \\
\hline Nagelhout et al. [33] & I & NL & 2001-2008 & Smoking prevalence & $\begin{array}{l}\text { Workplace smoking bans } \\
\text { Bans bars and restaurants }\end{array}$ & $\begin{array}{l}\text { Negative } \\
\text { No }\end{array}$ \\
\hline Anger et al. [3] & I & $\mathrm{DE}$ & $2002-2008$ & Smoking intensity & Smoke-free air & No \\
\hline Jones et al. [21] & I & UK & $1991-2007$ & Smoking prevalence & Public smoking bans & No \\
\hline Boes et al. [5] & I & $\mathrm{CH}$ & $2005-2011$ & Smoking prevalence & Public smoking bans & Negative \\
\hline Villar and Nicolás [44] & I & ES & 2006-2012 & Smoking prevalence & Bans public venues & Negative \\
\hline Cotti et al. [11] & I & US & 2004-2012 & Tobacco expenditures & $\begin{array}{l}\text { Taxes } \\
\text { Smoke-free air }\end{array}$ & $\begin{array}{l}\text { Negative } \\
\text { No }\end{array}$ \\
\hline DelBono et al. [15] & I & IT & 1999-2005 & Smoking behavior & Public smoking ban & No \\
\hline $\begin{array}{l}\text { Meier et al. [30] } \\
\text { b. Smoking dynamics }\end{array}$ & I & $\mathrm{CH}$ & 2001-2016 & Smoking prevalence & Ban youth tobacco sales & Small negative \\
\hline Douglas and Hariharan [17] & I & US & 1978-1997 & Initiation & Tobacco prices & No \\
\hline Douglas [16] & I & US & 1987 & Initiation and quits & $\begin{array}{l}\text { Tobacco prices } \\
\text { Smoking restrictions }\end{array}$ & $\begin{array}{l}\text { No } \\
\text { Positive (quits) }\end{array}$ \\
\hline Forster and Jones [18] & I & UK & 1984 & Initiation and quits & Tobacco prices & $\begin{array}{l}\text { Negative (initiation) } \\
\text { Positive (quits) }\end{array}$ \\
\hline López Nicolás [27] & I & ES & 1993-1997 & Initiation and quits & $\begin{array}{l}\text { Tobacco prices } \\
\text { Various bans }\end{array}$ & $\begin{array}{l}\text { Positive } \\
\text { Mixed }\end{array}$ \\
\hline DeCicca et al. [13] & I & US & 1988-1992 & Initiation & Tobacco prices & No \\
\hline Kidd and Hopkins [23] & I & $\mathrm{AU}$ & 1990-1998 & Initiation and quits & Tobacco prices & $\begin{array}{l}\text { Negative (initiation) } \\
\text { No (quits) }\end{array}$ \\
\hline Cawley et al. [7] & I & US & $1990-2000$ & Initiation & Tobacco prices & $\begin{array}{l}\text { Negative (males) } \\
\text { No (females) }\end{array}$ \\
\hline DeCicca et al. [14] & I & US & $1988-2000$ & Initiation and quits & Tobacco prices & $\begin{array}{l}\text { No (initiation) } \\
\text { Positive (quits) }\end{array}$ \\
\hline Nonnemaker and Farrelly [35] & I & US & 1997-2006 & Initiation & Tobacco prices & Negative \\
\hline Lillard et al. [25] & I & US & 1986-2007 & Initiation & Tobacco prices & Negative \\
\hline Marti [28] & I & $\mathrm{CH}$ & 2007 & Initiation and quits & TCP expenditures & $\begin{array}{l}\text { Negative (initiation) } \\
\text { Positive (quits) }\end{array}$ \\
\hline Guindon [20] & I & $\mathrm{VN}$ & 2003-2004 & Initiation & Tobacco prices & Negative \\
\hline Lillard and Önder [26] & I & TR & 2008 & Initiation and quits & Health warnings & $\begin{array}{l}\text { Mixed (initiation) } \\
\text { Positive (quits) }\end{array}$ \\
\hline
\end{tabular}

Data: $I$ individual/household, $S$ state/region averages

Country codes: $A U$ Australia, $C H$ Switzerland, $D E$ Germany, ES Spain, IT Italy, $N L$ Netherlands, TR Turkey, UK United Kingdom, US United States, $V N$ Vietnam

bans on smoking behavior concluding that the evidence is mixed. They revisit the effects of the 2005 smoking ban in Italy showing that the previous studies that focused on a before-after comparison overestimate the effects of the ban because of not taking seasonal differences in smoking behavior into account. From a difference-in-difference setup, it appears that the smoking ban had no impact on smoking behavior. Meier et al. [30] investigate the effects of a ban on the sales of tobacco to teens that was gradually introduced across Switzerland (and EU countries). They find that this 
ban caused a less than $1 \%$ point reduction in teen smoking attributing this small effect to teens circumventing the bans through peers.

\section{Smoking dynamics}

In addition to studies on prevalence and intensity of smoking, there are studies that focus on smoking dynamics. These studies are often based on cross-sectional data exploiting retrospective information about age of onset of smoking and the duration of smoking. DeCicca et al. [13] argue that their are clear differences between young and adults in the way prices affect smoking behavior. Since the onset of smoking is limited to early ages, for young smokers the main decision is whether or not to start smoking. For adult smokers, the decision is about intensity of smoking and about whether or not to quit smoking altogether. For youngsters, higher tobacco prices will reduce smoking mainly by preventing them to start smoking, while for adult smoking, higher tobacco prices will lead to cut down of quit smoking. According to Lillard et al. [25], models of smoking initiation based on longitudinal data are more relevant to policy analysis than models of the prevalence of smoking at a particular moment in time, because the decision to start smoking is different from the decision to continue smoking. Dynamics in smoking behavior have been studied using hazard rate models of smoking initiation sometimes in combination with hazard rate models of quitting smoking. Initially, the studies on smoking dynamics focused on the effect of cigarette prices only.

Panel b of Table 1 presents an overview of studies on smoking dynamics. Douglas and Hariharan [17] analyzing US data find that cigarette prices have no impact on smoking initiation. Douglas [16] analyzing US data finds no evidence of cigarette prices affecting smoking initiation, while quit rates increase with cigarette prices. Douglas [16] is among the few studies investigating the effects of nonprice tobacco control policies on the dynamics in smoking. ${ }^{2}$ He uses a state-specific smoking restrictiveness index and finds evidence that a more restrictive policy promotes quitting from smoking but does not deter the decision to start smoking. Forster and Jones [18] analyze British data finding that tobacco prices have a small negative effect on smoking initiation, while they have a more substantial positive effect on quit rates from smoking. López Nicolás [27] analyzes Spanish data to establish the price sensitivity of smoking dynamics finding that prices have a very small effect on the

\footnotetext{
2 Wilson et al. [47] provide an overview of 84 studies on the relationship between Tobacco Control Policies and smoking dynamics and prevalence of smoking. There are only a few studies on smoking initiation. Their main finding is that there is no clear relationship between smoking bans in public places and initiation into smoking.
}

propensity to start smoking, while an increase in the prices of the cheapest varieties of cigarettes encourages quitting from smoking. López Nicolás [27] also finds that the ban on smoking ads and smoking bans introduced in some public transport media in 1984 did not affect smoking dynamics, whereas the extension of the smoking bans to flights and intensified health warning campaigns a few years later seem to have had an effect on both starting and quitting. DeCicca et al. [13] find no effects of tobacco prices on the onset of smoking among US youngsters. Kidd and Hopkins [23] analyzing Australian data find that tobacco prices affect the onset of smoking but not the quit rate. Based on an analysis of US data, Cawley et al. [7] conclude that smoking initiation among males is negatively affected by cigarette prices, while these have no impact on smoking initiation among females. DeCicca et al. [14] also find no effect of tobacco prices on the onset of smoking although this study does find that higher tobacco prices are associated with increase quitting from smoking. Nonnemaker and Farrelly [35] find significant albeit small effects of tobacco prices on smoking initiation. Lillard et al. [25] argue that other studies may not have found an effect of prices on smoking initiation because of limited policy variation over the calendar time periods studied. They themselves use three datasets to allow for more calendar time variation in policies finding negative and significant price effects on smoking initiation. Marti [28] estimates the dynamics of smoking in Switzerland using tobacco control spending as one of the explanatory variables and finding that these affect both smoking initiation and quitting from smoking. Guindon [20] studies the impact of tobacco prices on the onset of smoking in Vietnam finding significant and substantial effects. Lillard and Önder [26] investigate the effects of information about health risks of smoking in Turkey finding that as new information arrives all smokers are more likely to quit smoking, while female non-smokers are less likely to start.

\section{A simple model of smoking initiation}

A model of smoking initiation has to take into account that individuals start smoking in their teens or early twenties. If an individual has not started smoking in this age range, smoking initiation later on in life is very unlikely [43]. This implies that over a relatively short age range individuals balance marginal costs and marginal benefits of smoking initiation. Apparently, from a certain age onward, this balance is negative, i.e., individuals will refrain from smoking. Or, alternatively, individuals are no longer facing the balancing question as they already made up their mind that for the rest of their life it is better to abstain from smoking. It is also possible that for some individuals the costs of starting to smoke always outweighs potential benefits, i.e., they 
realize from early on in life that there are no utility gains in smoking initiation. And, it is also possible that later on in life individuals are no longer confronted with invitations to start smoking, because most or perhaps, all of their friends, family, and colleagues are non-smokers.

We present a simple model of smoking initiation with the purpose of illustrating how tobacco control policies may affect smoking initiation. We assume that individuals are confronted with a flow of smoking opportunities. ${ }^{3}$ The arrival rate of smoking opportunities is likely to be agedependent. According to Suranovic et al. [42], individuals in their early teens expect no benefits of smoking and, therefore, have no interest in starting to smoke. If friends start smoking and encourage participation, youngsters may start to think that smoking has potential benefits. Furthermore, teenagers may experience peer pressure or follow the example of their parents. Conditional on having an opportunity to start smoking an individual will balance marginal benefits and marginal costs of doing so.

According to Douglas and Hariharan [17] a rational individual will start smoking if and only if the marginal benefit of the first cigarette is larger than its marginal cost:

$\operatorname{MB}_{t}\left(C_{t}, Y_{t}, L_{t}\right)>\operatorname{MC}_{t}\left(C_{t}, Y_{t}, L_{t}\right)$

where $C$ represents the consumption of a cigarette, $Y$ is the consumption of other goods, $L$ represents other life cycle events that affect utility, and $t$ represents time. ${ }^{4}$ Both marginal cost and marginal benefits may be influenced by variables that have a stochastic component. Therefore, Eq. (1) can be divided into a non-stochastic and a stochastic component:

$\mathrm{MB}_{t}^{*}+\varepsilon_{t}>\mathrm{MC}_{t}^{*}+\mu_{t}$

\footnotetext{
3 This is similar to job finding theory, where unemployed workers receive a stream of random wage offers from a distribution with certain characteristics. Conditional on the arrival rate of job offers, search costs and the wage distribution the individual decides which wage offers to accept. Of course there are many differences as well. Unemployed search for opportunities to make a transition from unemployment to work, while non-smoking individuals may not be interested per se in a transition to becoming a smoker.

${ }^{4}$ Once an individual has started smoking, decisions to keep smoking later on depend on the stock of addictive capital based on the number of cigarettes smoked. Equation (1) is about smoking initiation, so the stock of addictive capital is zero. Darden [12] presents a dynamic model of lifetime smoking behavior focusing on the response of smokers to updated information on their health. Odermatt and Stutzer [36] suggest that a behavioral approach to tobacco control policies may be relevant. Using data from 22 European countries, they relate tobacco control policies to life satisfaction finding no significant effects. Only for smokers who would prefer to stop smoking permanently there is a beneficial effects of smoking bans, a finding which the authors relate to the possibility that smoking bans serve as a selfcontrol device.
}

where $\mathrm{MB}_{t}^{*}$ and $\mathrm{MC}_{t}^{*}$ are the expected marginal benefits and costs of smoking. The probability of smoking initiation at time $t$ can be written as

$$
\begin{aligned}
\operatorname{Pr}\left(C_{t}>0\right) & =\operatorname{Pr}\left(\mathrm{MB}_{t}^{*}+\varepsilon_{t}>\mathrm{MC}_{t}^{*}+\mu_{t}\right) \\
& =\operatorname{Pr}\left(\mathrm{MB}_{t}^{*}-\mathrm{MC}_{t}^{*}>\mu_{t}-\varepsilon_{t}\right) \\
& =F\left(\mathrm{MB}_{t}^{*}-\mathrm{MC}_{t}^{*}\right)
\end{aligned}
$$

where $F$ is a distribution function. The probability of smoking at time $t$ conditional on not having smoked until then can also be written as a hazard function in which the opportunity arrival rate $\psi_{t}$ is taken into account:

$\theta(t)=\psi_{t} F\left(\mathrm{MB}_{t}^{*}-\mathrm{MC}_{t}^{*}\right)$

where $\theta(t)$ is the smoking initiation rate. $\mathrm{As}^{\mathrm{M}} \mathrm{B}_{t}^{*}-\mathrm{MC}_{t}^{*}$ increases or the opportunity arrival rate goes up, the hazard rate of smoking initiation increases, and thus the probability to start smoking increases.

To explain the pattern of smoking initiation from the mid teens to the early twenties one has to assume that the opportunity arrival rate has a peak in this age range or the difference between marginal benefits and marginal costs is positive only in this age interval. It may also be that opportunities are less likely to arrive for early teens or beyond early twenties. Perhaps, peer groups influence smoking behavior such that non-smokers hang-out or are partnered with nonsmokers and individuals who have never smoked are less likely to be confronted with an opportunity.

In their rational addiction model, Orphanides and Zervos [37] introduce heterogeneity across individuals on the basis of addictive tendencies. There are non-addicts and potential addicts. Before, they start using an addictive good, individuals are uncertain about their addictive tendency. If an individual is of the addictive type (s)he will experience a negative utility effect related to the detrimental addictive side effects of past consumption. Individuals may fear to be of the addictive type and, therefore, abstain from starting to smoke. ${ }^{5}$ An alternative explanation for the observed age pattern of smoking initiation is that there is heterogeneity in individual behavior such that for some individuals marginal costs are always larger than marginal benefits, and therefore, they abstain from smoking. If for other individuals marginal benefits of smoking initiation are larger than marginal costs in the relevant age range, all these individuals will end up becoming smokers in their teens or early twenties. Then, the observed pattern of smoking

\footnotetext{
${ }^{5}$ Other individuals may start smoking, find out that they are of the addictive type and then regret their original decision. Regret may also have a different origin. Suranovic et al. [42], for example, assume bounded rationality such that individuals focus on decisions about current smoking rather than taking future smoking into account. Then, it is possible that later in life individuals regret decisions they made when they were young.
} 
Table 2 Information about nonprice tobacco control policies: first year in which a policy was implemented Source: Nguyen et al. [34]; see also "Appendix B"

\begin{tabular}{lllll}
\hline & Smoke-free air & $\begin{array}{l}\text { Large direct } \\
\text { health warning } \\
\text { labels }\end{array}$ & $\begin{array}{l}\text { Comprehensive bans on } \\
\text { advertising and promotion }\end{array}$ & $\begin{array}{l}\text { Treatments to help } \\
\text { dependent smokers } \\
\text { stop }\end{array}$ \\
\hline Austria & 1994 & 1974 & 1994 & 2001 \\
Germany & 1971 & 1976 & 1976 & 1976 \\
Finland & 1991 & 1975 & 1990 & 1974 \\
France & 2001 & 1981 & 1973 & 1998 \\
Ireland & 1994 & 1990 & 1970 & 1991 \\
Italy & 1974 & 1992 & 1982 & 1983 \\
Netherlands & 1989 & 1989 & 1989 & 1995 \\
Portugal & 1982 & 1990 & 1982 & 2001 \\
Spain & 1987 & 1987 & 1993 & 1990 \\
Sweden & 1993 & 1973 & 1993 & 1969 \\
United Kingdom & 2003 & 1990 & 1989 & 1986 \\
\hline
\end{tabular}

initiation is caused by one group of individuals who all start smoking in the relevant age range and another group of individuals who abstain from smoking throughout their life.

In our simple model of smoking initiation it is clear how tobacco control policies may influence decision making of individuals. Tobacco prices will increase marginal costs of smoking initiation and, therefore, reduce the probability that an individual will start smoking at a certain age. Individuals may take future tobacco prices into account as well. If so, this will affect the marginal costs more strongly. The nonprice tobacco control policies may affect marginal benefits and/or marginal costs of smoking initiation. All of these policies provide information about the negative health consequences of smoking and, therefore, increase the perceived marginal costs of smoking. In addition to this, smoke-free air laws may reduce marginal benefits of smoking as smoking is no longer possible in certain public domains. Bans on advertising promotion and sponsorship may be beneficial to early teens, since without advertising, they may not be tempted to think that smoking may be fun. Health warnings on tobacco product packaging will increase the perceived costs of smoking but may also reduce the marginal benefits of smoking as the pleasure derived from smoking goes down. Finally, smoking cessation treatment policies, i.e., programs to help dependent smokers stop smoking may be informative to nonsmokers about potential addiction and, therefore, not only increase marginal costs but also reduce marginal benefits from smoking initiation.

\section{Smoking in Europe}

\section{Tobacco control policies and prevalence of smoking}

Nowadays, strict regulations on tobacco use are common. Only a few decades ago this was not the case. Up to the 1960s, there were almost no tobacco control policies, neither on smoking in the public domain nor on advertising, as knowledge about the negative health consequences of smoking was limited. In the United States, the 1964 Surgeon General's report gradually changed the public opinion about tobacco use when it became clear that there are several adverse health consequences related to smoking.

Also in Europe, concerns about negative health consequences of tobacco use started in the 1960s. However, this lead only to some minor regulations in a few countries that advocated smoking cessation and restricted advertisements on tobacco. For a long time, economic interests dominated concerns over health consequences of smoking. The "golden years of tobacco" lasted until the mid-1980s when the European Union (EU) started to implement restrictive tobacco control policies by passing legislation and making tobacco control policies a part of European Union law.

Table 2 shows that the first tobacco control policies implemented were mainly bans on advertisement and health warnings on packages. Among the eleven European countries in our empirical analysis, six had already passed some restrictive regulations on tobacco advertisements in 1985, five had done so a few years later. By 1990, almost all countries had meaningful restrictions on advertisement and health warnings on packages. The first country to implement any tobacco control policy was Sweden by passing a law restricting tobacco advertisements in 1969. The last country to implement any tobacco control policy was The Netherlands in 1989. The late introduction may be related to The Netherlands for a long time being the second largest producer of tobacco products and the second largest exporter of cigarettes.

To establish how smoking initiation is affected by tobacco control policies, we use the Tobacco Control Policy Index (TCPI) as an indicator. The TCPI has four main components: smoke-free air laws, comprehensive 
bans on advertising and promotion, health warnings on tobacco product packaging and treatment to help dependent smokers stop. Nguyen et al. [34] created the TCPI adopting the scoring system introduced by Joossens and Raw [22]. It allocates points to several components of each policy. Smoke-free air laws policy, for example, has four components: Bans in cafes and restaurants, bans in public transport, bans in other public places and bans in workplaces excluding cafes and restaurants. The comprehensive bans on advertising and promotion include bans on radio and television, print media, cinema, sponsorship etc. The health warning labels on tobacco products vary by size, color and pictures. Finally, the treatments to help dependent smokers stop include quit lines and reimbursement of treatment and medications

The overall index reflects the sum of the scores given to each of the four policies which themselves are sums of the scores given to each of the components (see "Appendix B" for details). Since the same scoring system is used for all countries, the index can be used for cross-country comparisons of the strictness of tobacco control policies. Clearly, the TCP index has its limitations. The way various components are calculated is somewhat arbitrary. Furthermore, the index does not include information about the enforcement of various policies. Finally, two countries can have the same score even though they apply different tobacco control policies. Therefore, in a sensitivity analysis we also investigate the separate effects of each of the four main components.

Figure 1a displays the evolution of the TCPI in eleven European countries from 1950 until 2010. Before 1969, the index remains at zero, because there was no tobacco control policy in any of the eleven countries. After 1969 the index slightly increases in many countries, and after 1990 it increases rapidly. There is substantial variation between countries for all tobacco control policies as the first implementation dates and the levels of policy scores differ considerably. Such differences also exits in the tobacco prices. Figure $1 \mathrm{~b}$ displays the trends in real tobacco prices in eleven countries. Even though real prices of tobacco have been increasing over time in all countries, the increase is much steeper in countries such as Finland and United Kingdom than it is in other countries.

Figure 2 provides information about smoking prevalence, i.e., the percentages of current smokers in the population over 15 years of age. There are clear differences between countries and between males and females. For males, the highest smoking prevalence is in Austria, France and Spain, with more than $30 \%$ currently smoking. In Sweden and the UK less than $20 \%$ of the adult males smoke. For females, the highest smoking prevalence of $25 \%$ or more is in Austria and France, the lowest with $13 \%$ is in Portugal. In all countries females are less likely to smoke than males although in Sweden the difference is only $1 \%$-point. a Tobacco Control Policy index

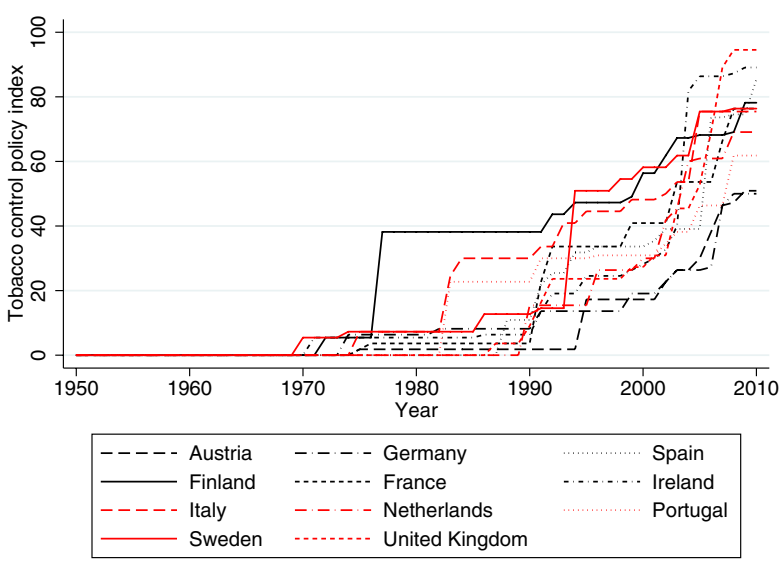

b Tobacco prices

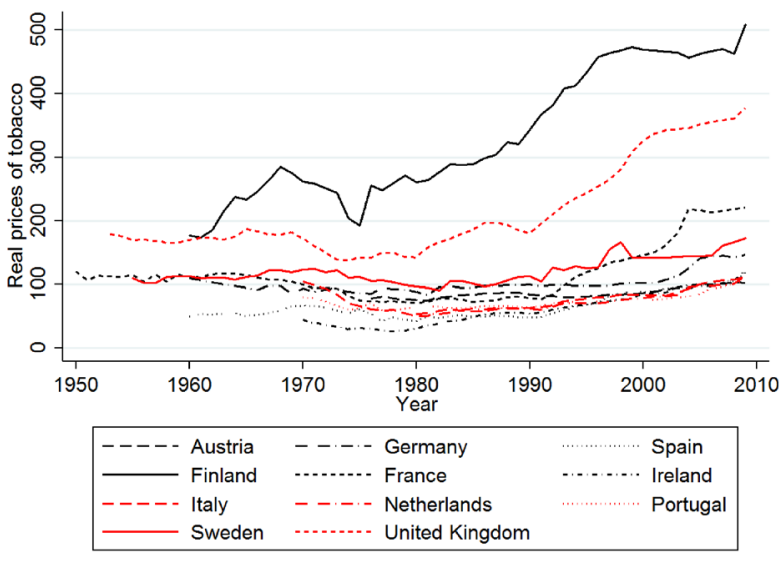

Note: The development of the separate indexes of tobacco control policies in each of the countries is presented in (web)appendix C. For Italy, Portugal and Spain the real price index is for tobacco, for the other countries the price index is for cigarettes.

Fig. 1 Tobacco Control Policy index and tobacco prices in eleven European countries; 1950-2010

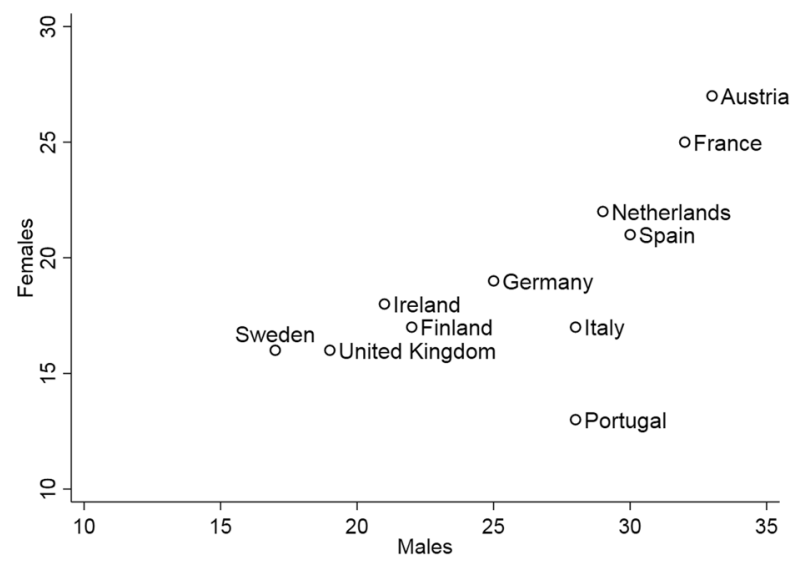

Note: Intormation from 2014; source except Ireland: Eurostat. Source Ireland: National Tobacco Control Office.

Fig. 2 Current smokers (percentage of population over 15 years of age) 
Table 3 Cumulative probability to have started smoking by ages of $15,20,25$ and 30

\begin{tabular}{|c|c|c|c|c|c|c|c|c|}
\hline \multirow[t]{2}{*}{ Age } & \multicolumn{4}{|c|}{ Females } & \multicolumn{4}{|c|}{ Males } \\
\hline & 15 & 20 & 25 & 30 & 15 & 20 & 25 & 30 \\
\hline Austria & 4 & 38 & 39 & 39 & 8 & 41 & 43 & 43 \\
\hline Finland & 10 & 44 & 47 & 48 & 11 & 40 & 50 & 52 \\
\hline France & 12 & 42 & 52 & 54 & 15 & 52 & 61 & 63 \\
\hline Germany & 8 & 39 & 42 & 43 & 12 & 46 & 50 & 51 \\
\hline Ireland & 6 & 34 & 39 & 39 & 7 & 33 & 40 & 41 \\
\hline Italy & 3 & 24 & 33 & 35 & 7 & 32 & 37 & 37 \\
\hline Netherlands & 14 & 42 & 48 & 49 & 16 & 44 & 49 & 54 \\
\hline Portugal & 7 & 31 & 36 & 37 & 8 & 43 & 49 & 50 \\
\hline Spain & 12 & 39 & 42 & 42 & 13 & 42 & 47 & 49 \\
\hline Sweden & 7 & 29 & 37 & 38 & 10 & 35 & 40 & 41 \\
\hline United Kingdom & 13 & 33 & 38 & 39 & 5 & 37 & 43 & 44 \\
\hline
\end{tabular}

Source: Authors' calculation based on a Kaplan-Meier survivor function estimator using Eurobarometer (429) data. The standard error of each estimate is about 3-4\%-point. Therefore, not all cross-country estimates are significantly different from each other. The starting rates and cumulative starting probabilities of smoking in each of the countries is presented in (web)appendix $\mathrm{C}$

\section{Smoking initiation}

To study the uptake of smoking, we use data from a special Eurobarometer (429) covering residents in EU member states aged 15 years and over. ${ }^{6}$ These data collected in November/December 2014 through face-to-face interviews in people's homes focused on attitudes towards tobacco and electronic cigarettes. The starting point of the survey was the question "Regarding smoking cigarettes, cigars, cigarillos or a pipe, which of the following applies to you?"7 If the answer was "currently smoke" or "used to smoke but has stopped", the following question was "How old were you when you started smoking on a regular basis, i.e., at least once a week?" We use this retrospective information to reconstruct the history of smoking initiation necessary to model the starting rates of tobacco use.

The data we use are from eleven European countries for which we have information on tobacco control policies and tobacco prices. In our baseline estimates, we restrict our sample to individuals born from 1970 onward. As Table 3

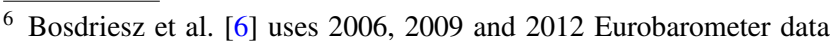
from 27 European countries to study the effect of tobacco control policies and quit ratio defined as the ratio of the number of former smokers and the sum of the numbers of former and current smokers. The tobacco control policies are specified on a scale from 0 to 100 based on expert opinions on six domains: tobacco price, smoke-free areas, tobacco control budget, bans on tobacco advertising, health warning labels and support to stop smoking (cessation programs). Bosdriesz et al. [6] find an association between their measure of tobacco control policies and smoking cessation for higher educated individuals but not for individuals with lower and intermediate education.

7 To this question was added that "Smoking cigarettes does not include use of electronic cigarettes."
}

shows, the age pattern of smoking initiation is very similar across the countries. There is a strong increase between age 15 and 20, a slight increase between age 20 and 25 and a very small increase later on. However, there are big crosscountry differences in cumulative starting probabilities by age 30. For males, the share of the population that has ever smoked or is still smoking ranges from $37 \%$ in Italy to $54 \%$ in The Netherlands. For females it ranges from $35 \%$ in Italy to $54 \%$ in France. ${ }^{8}$

\section{Empirical analysis}

\section{Setup empirical analysis}

In our empirical analysis, we use a mixed proportional hazard model with a fully flexible baseline specification. Since the underlying dynamics of smoking initiation are expected to be gender-specific, we perform a separate analysis for males and females. In this setup, the duration of stay in the non-smoking state is equivalent to the age of the individual, where we assume that individuals are exposed to possible initiation to smoking from age eleven onward. The starting rate of smoking at time $t(t=0$ at age eleven) of individual $i$ in country $j$ conditional on observed individual characteristics $x$, tobacco control policy index $B$, real tobacco price $P$ and unobserved individual characteristics $u$ is defined as

\footnotetext{
${ }^{8}$ Note that, as indicated in the footnote to Table 3, we used a KaplanMeier survivor function estimator to calculate the cumulative probabilities. The standard error of each estimate is about 3-4\%-point. Therefore, not all cross-country estimates are significantly different from each other.
} 
$\theta\left(t \mid x_{i}, B_{i j t}, P_{i j t}, u_{i}\right)=\lambda_{i}(t) \exp \left(\alpha_{j}+x_{i}^{\prime} \beta+\delta B_{i j t}+\rho \log \left(P_{i j t}\right)+u_{i}\right)$

where $\alpha_{j}$ represents country fixed effects to allow for unobserved time-invariant differences between countries. ${ }^{9}$ Furthermore, $\delta$ measures the effect of non-price tobacco control policies, $\rho$ measures the effect of prices, and $B_{i j t}$ and $P_{i j t}$ are time varying variables which capture within country calendar time variation of smoking restrictions and tobacco prices. Although within a country in a particular year the same smoking restrictions apply to all individuals in that country, the effect of a smoking restriction at a particular age depends on the year of birth of the individual. Therefore, the tobacco control policy at any given age is country-specific and individual-specific. Parameter $\rho$ measures the effect of tobacco prices, where $\log \left(P_{i j t}\right)$ is the natural logarithm of the real prices of tobacco. Again, the calendar time variation in tobacco control policies is translated into age-specific variation, because a change in tobacco control policy index in a particular year affects individuals from different birth years at a different age. The age variation in the tobacco control policies is country-specific, since there is variation in the years in which these policies were introduced. Identification of the non-price tobacco control policies comes from cross-country variation in the timing of these policies and the cross-individual variation over age when these policies were implemented. In other words, we use a before-after approach in a hazard rate framework, where the before-after variation is caused by the introduction of tobacco control policies in a particular year and in a particular country. This induces an age-specific shift in the starting rate of smoking. The observed characteristics $x$ refer to education, birth year and degree of urbanization of the place of residence (see "Appendix A" for details). The vector of parameters $\beta$ represents the effects of other control variables including country-specific birth year trends. Furthermore, $\lambda_{i}(t)$ represents individual duration dependence. As indicated before, we assume that everyone becomes vulnerable to the risk of initiation into smoking at age eleven. This is because in all of the countries, almost no one starts using tobacco before the age of eleven. Because of this assumption, the duration dependence actually becomes age dependence. Finally, $u_{i}$ denotes individual unobserved heterogeneity in the starting rates of tobacco use which we model as random effects. They control for differences in time-invariant unobserved susceptibility of individuals to tobacco use. Note that the decision to start smoking often occurs before an individual obtains his or her final educational attainment. Therefore, we assume educational attainment to be an indicator of

\footnotetext{
9 DeCicca et al. [13] find that once they include state fixed effects in their hazard rate analysis, the significant effect of tobacco taxes on initiation into smoking disappears.
}

cognitive ability. By way of sensitivity analysis we also did estimates excluding educational attainment as an observed characteristic, finding similar results.

Duration dependence is specified in a fully flexible way by means of a step function:

$\lambda_{i}(t)=\exp \left(\sum_{k} \lambda_{i k} I_{k}(t)\right)$

where $k(=1, \ldots, 11)$ is a subscript for age categories starting from age 11 and $I_{k}(t)$ are time-varying dummy variables that are one in subsequent categories, 10 of which are for individual ages or age intervals (age 11 and $12, \ldots, 17,18-19$, 20-22) and the last interval is for ages above 22 years. Because we estimate a constant term in the analysis, we normalize $\lambda_{i, 1}=0$.

The conditional density function of the completed durations until the first use of tobacco can be written as

$$
\begin{gathered}
f\left(t \mid x_{i}, B_{i j t}, P_{i j t}, u_{i}\right)=\theta\left(t \mid x_{i}, B_{i j t}, P_{i j t}, u_{i}\right) \\
\exp \left(-\int_{0}^{t} \theta\left(s \mid x_{i}, B_{i j t}, P_{i j t}, u_{i}\right) \mathrm{d} s\right)
\end{gathered}
$$

We integrate out the unobserved heterogeneity such that density function for the duration until tobacco uptake $t$ conditional on $x$ becomes

$f\left(\mid x_{i}, B_{i j t}, P_{i j t}\right)=\int_{u_{i}} f\left(t \mid x_{i}, B_{i j t}, P_{i j t}, u_{i}\right) \mathrm{d} G\left(u_{i}\right)$

where $G(u)$ is assumed to be a discrete mixing distribution with 2 points of support $u_{1}$ and $u_{2}$. This reflects the presence of two types of individuals in the hazard rate for tobacco uptake. The associated probabilities are denoted as follows: $\operatorname{Pr}\left(u=u_{1}\right)=p$ and $\operatorname{Pr}\left(u=u_{2}\right)=1-p$, where $p$ is modeled using a logit specification, $p=\frac{\exp (\alpha)}{1+\exp (\alpha)}$. Individuals who do not start using tobacco until the time of the survey are considered to have right-censored durations until smoking initiation. The inflow nature of the data guarantees that there are no left censored individuals.

\section{Baseline parameter estimates}

Table 4 presents our baseline parameter estimates obtained by the method of Maximum Likelihood. The first column presents the parameter estimates for males, the second column for females. ${ }^{10}$ Panel a of Table 4 contains the baseline

\footnotetext{
$\overline{10}$ We also did a joint estimate pooling males and females and introducing a dummy variable for females. The results show that conditional on having the same parameters for males and females, females have a lower starting rate for smoking. However, the Likelihood Ratio statistic for comparing the separate estimates with the joint estimate
} 
Table 4 Baseline parameter estimates mixed proportional hazard model

\begin{tabular}{lrlrl}
\hline & Males & \multicolumn{3}{c}{ Females } \\
\hline Tobacco control policies & -0.04 & $(0.8)$ & -0.05 & $(1.2)$ \\
Tobacco prices & -0.14 & $(2.8)^{* *}$ & 0.05 & $(0.7)$ \\
Education 2 & -0.72 & $(3.4)^{* *}$ & -0.63 & $(3.3)^{* *}$ \\
Education 3 & -1.84 & $(8.4)^{* *}$ & -1.47 & $(7.2)^{* *}$ \\
Education 4 & -2.20 & $(8.5)^{* *}$ & -1.56 & $(5.9)^{* *}$ \\
Small/mid town & 0.17 & $(1.3)$ & 0.32 & $(2.2)^{* *}$ \\
Large town & -0.01 & $(0.1)$ & 0.29 & $(2.2)^{* *}$ \\
Age 12 & 0.37 & $(1.1)$ & 0.58 & $(1.6)$ \\
Age 13 & 1.75 & $(5.4)^{* *}$ & 1.53 & $(4.4)^{* *}$ \\
Age 14 & 2.52 & $(8.1)^{* *}$ & 2.40 & $(7.2)^{* *}$ \\
Age 15 & 3.01 & $(9.6)^{* *}$ & 3.16 & $(9.5)^{* *}$ \\
Age 16 & 3.47 & $(10.9)^{* *}$ & 3.81 & $(11.5)^{* *}$ \\
Age 17 & 3.37 & $(10.2)^{* *}$ & 4.10 & $(11.9)^{* *}$ \\
Age 18 & 3.60 & $(10.6)^{* *}$ & 4.41 & $(12.2)^{* *}$ \\
Age 19 & 3.19 & $(8.8)^{* *}$ & 4.19 & $(10.6)^{* *}$ \\
Age 20+ & 1.27 & $(3.0)^{* *}$ & 2.04 & $(4.6)^{* *}$ \\
$u_{2}$ & -3.19 & $(11.5)^{* *}$ & -3.84 & $(20.6)^{* *}$ \\
$\alpha$ & 0.04 & $(0.3)$ & -0.75 & $(11.1)^{* *}$ \\
-LogLikelihood & 3541.8 & & 3962.9 & \\
Observations & 2065 & & 2442 & \\
\hline & & & & \\
\hline
\end{tabular}

All estimates contain country fixed effects and country-specific birth year trends; in parentheses absolute t-statistics;

** (*): significant at a 5\% (10\%) level

parameter estimates in which we focus on the aggregate indicator for tobacco control policies. Parameter estimates of the country fixed effects and the country-specific birth year trends are not reported. Our main parameter of interest, related to the tobacco control policies index is negative but insignificantly different from zero for both males and females. Parameter estimates for tobacco control policies are economically insignificant as well. A complete smoking ban in public transportation services, for example, corresponds to around $0.1 \%$ decrease in the smoking initiation hazards. ${ }^{11}$

Tobacco prices have a negative effect for males but not for females. It is not clear why the effect of tobacco prices is gender-specific. However, it is not a surprising result as the same result was found by Cawley et al. [7]. We can only speculate that it is related to the different developments in smoking prevalence. Contrary to the developments for

\footnotetext{
Footnote 10 (continued)

is equal to 74.0 which is significant at a $5 \%$-level (critical $\chi^{2}$-value with 40 degrees of freedom is 55.8). Therefore, we proceed with the separate estimates for males and females.

${ }^{11}$ In TCPI indices a smoking ban in public transportation services corresponds to a score of 2.2 out of 100 .
}

males, in the past decades, smoking of females has increased a lot. It could be that the effect of tobacco prices on smoking initiation is mitigated because of this growth. Because of this, the age of onset of smoking goes up with tobacco prices for males but not for females. As to the personal characteristics, for males and females a lower educational attainment has a positive effect on the smoking initiation rate. Higher education-which we assume to be an indication of ability-has a negative effect on the smoking initiation rate. Females in big cities have a higher starting rate. For males, we do not find any effect for urbanization. The age dependence pattern reflects the age-related fluctuations in the smoking initiation rates. Parameter estimates for unobserved heterogeneity show that for both males and females there is unobserved heterogeneity in the starting to smoke rate. Among the males, $54 \%$ has a high starting rate, while $46 \%$ has a low starting rate. Among females, these shares are 39 and 61 , respectively. The starting rate of the second group is much smaller than the starting rate of the first group. This implies that although some individuals have a positive probability to start smoking, this probability is so small that they will never do that (see Abbring [1] for a discussion on the distinction between ex ante abstainers and ex post abstainers.)

Quite a few of our findings are in line with the results from the previous studies. For example, the negative effect of educational attainment on smoking initiation is a familiar finding. Also, as discussed earlier, the gender-specific differences in the effect of tobacco prices on smoking initiation is a result that has been established before. The finding that tobacco control policies other than tobacco prices for males have no effect on smoking initiation confirms the results of some but contradicts the results of some other studies. As indicated in "Previous studies", where we reviewed earlier studies on the effect of tobacco control policies there is no common conclusion. Depending on the particular policy sometimes there are even mixed findings within one particular study. Nevertheless, it should be noted that whereas the previous studies often focus on one particular tobacco control policy in one particular country we investigated how overall tobacco control policies affected smoking initiation in a cross-country analysis.

\section{Sensitivity analysis}

The main finding in our baseline estimates is that tobacco prices have a negative effect on smoking initiation of males but have no effect on smoking initiation of females. Furthermore, tobacco control policies do not affect smoking initiation. Neither for males nor for females. Since we want to be sure that these main findings do not depend on peculiarities of our analysis we performed a wide range of sensitivity analysis. There is a variety of potential confounders 
Table 5 Parameter estimates effect tobacco control policies; sensitivity analysis

\begin{tabular}{|c|c|c|c|c|c|c|c|c|c|c|}
\hline & \multicolumn{5}{|l|}{ Males } & \multicolumn{5}{|l|}{ Females } \\
\hline & TCP & & Prices & & $-\log L$ & TCP & & Prices & & $-\log \mathrm{L}$ \\
\hline \multicolumn{11}{|l|}{ a. Alternative specifications } \\
\hline 1. General birth year trend & 0.06 & (1.6) & -0.13 & $(1.8)^{*}$ & 3553.0 & -0.02 & $(0.1)$ & 0.07 & $(0.2)$ & 3974.5 \\
\hline $\begin{array}{l}\text { 2. General calendar time trend } \\
\text { b. Type of TCP }\end{array}$ & -0.04 & $(0.7)$ & -0.21 & $(2.8)^{* *}$ & 3541.8 & -0.05 & $(1.2)$ & 0.07 & $(0.6)$ & 3962.9 \\
\hline 1. Smoke-free & -0.03 & $(0.8)$ & -0.21 & $(2.8)^{* *}$ & 3541.8 & -0.01 & $(0.5)$ & 0.07 & $(0.9)$ & 3963.5 \\
\hline 2. Advertising & 0.01 & $(0.2)$ & -0.20 & $(2.7)^{* *}$ & 3542.1 & 0.02 & $(1.2)$ & 0.04 & $(0.5)$ & 3963.0 \\
\hline 3. Health warnings & -0.03 & $(0.6)$ & -0.20 & $(2.7)^{* *}$ & 3541.9 & -0.01 & (1.4) & 0.05 & $(0.7)$ & 3963.2 \\
\hline $\begin{array}{l}\text { 4. Stop smoking treatment } \\
\text { c. Additional sensitivity analysis }\end{array}$ & -0.05 & $(1.1)$ & -0.19 & $(2.6)^{* *}$ & 3541.5 & -0.05 & (1.5) & 0.05 & $(0.7)$ & 3963.3 \\
\hline 1. Any TCP & 0.03 & $(1.5)$ & -0.21 & $(2.8)^{* *}$ & 3541.2 & -0.08 & $(0.4)$ & 0.05 & $(0.7)$ & 3963.4 \\
\hline 2. Bans in public places & -0.01 & $(0.1)$ & -0.20 & $(2.7)^{* *}$ & 3542.1 & 0.02 & $(0.2)$ & 0.05 & $(0.6)$ & 3963.4 \\
\hline 3. Bans in workplaces & -0.01 & $(0.2)$ & -0.20 & $(2.7)^{* *}$ & 3542.2 & 0.02 & $(1.5)$ & 0.05 & $(0.6)$ & 3962.5 \\
\hline 4. Birth year from 1960 & -0.04 & $(0.7)$ & -0.09 & $(1.7)^{*}$ & 6028.2 & -0.02 & $(0.6)$ & 0.05 & $(0.6)$ & 4734.6 \\
\hline 5. Birth year from 1950 & -0.03 & $(0.2)$ & -0.08 & (1.4) & 4647.4 & -0.04 & $(1.0)$ & 0.08 & $(1.1)$ & 4187.8 \\
\hline
\end{tabular}

All estimates contain country fixed effects and (apart from panel a1) country-specific birth year trends as well as the other individual characteristics presented in Table 4 . The estimates and panels a, b and c1-c3 are based on 2065 males and 2442 females. In estimation $c 4$, the numbers of observations are 3075 for males and 2815 for females; countries excluded due to the unavailability of the price information are Austria and The Netherlands. In estimation c5, the numbers of observations are 2270 for males and 2297 for females; countries excluded due to the unavailability of the price information are Austria, Ireland, Italy, Portugal and The Netherlands. In parentheses absolute t-statistics

$* *(*)$ : significant at a $5 \%(10 \%)$ level

that might cause a spurious lack of effect for tobacco control policies on smoking initiation other than the negative effect of prices for males. It is possible that ignoring calendar time trends representing a changing attitude toward smoking absorbs the effect of tobacco control policies. Therefore, we investigated whether our results depend the inclusion of a calendar time trend in the hazard rate models. Another possibility is that different control policies have opposite effects on smoking initiation. If so, these effects could cancel out when different policies are combined into one indicator. Therefore, we investigated whether specific tobacco control policies matter. Finally, it is possible that our findings are specific for young birth cohorts or specific countries. Therefore, we investigated whether our findings change if we include older birth cohorts in the analysis. Since these are only available for a subset of countries this sensitivity analysis also provides information about the robustness of our findings when we exclude some countries from the analysis.

As a first check on the robustness of our findings, we estimated the same models with slightly different specifications. Panel a of Table 5 shows how the effect of the TCPI is influenced by changes in the specification of birth year and calendar time trend. In panel a1 the country-specific birth year trends are replaced by a common birth year trend. In panel a2, the country-specific birth year trends are reintroduced in addition to a general calendar time trend. The parameter estimates of the TCPI are not very much affected. For males, replacing the country-specific birth year trends by a common birth year trend changes the sign of the TCPI parameter but this is still insignificantly different from zero. The introduction of a calender time trend is not very important. For females all parameter estimates of the TCPI-index are very much the same, i.e., small and insignificantly different from zero.

To further investigate the robustness of our findings we performed a range of sensitivity analysis. In panel $b$ of Table 5 we report the effects of particular types of tobacco control policies: smoke-free air laws, bans on advertising promotion and sponsorship, health warnings on tobacco product packaging and stop smoking treatment policies. Both for males and females, none of the separate tobacco control policies has an effect on the age of initiation to smoking.

Panel c of Table 5 presents further sensitivity outcomes. In panels $\mathrm{c} 1$ to $\mathrm{c} 3$ the tobacco control policy index is replaced by a dummy variable. In panel c1 the dummy variable is 1 if any tobacco control policy is implemented. In panel c2 it is 1 if smoking is banned in public places, in estimation $\mathrm{c} 3$ it is 1 if smoking is banned in workplaces. Therefore, in these estimations, we compare the age of onset of smoking for individuals before and after a tobacco control policy is implemented. The parameter estimates show that our conclusion remains the same. In panels c4 and c5 we also use information on older cohorts, those who were born after 1959 and after 1949, respectively. In some countries the information on tobacco prices is not available for early 
years, in which case we exclude these countries from this part of the analysis. In panel c4, countries excluded due to the unavailability of the price information are Austria and The Netherlands. In panel c5, Austria, Ireland, Italy, Portugal and The Netherlands are excluded. Although the sample sizes and cohort structure considerably change, our conclusions remain same. This sensitivity analysis also shows that a possible recall bias due to the self-reporting of the data is not an issue. And, it shows that our findings are robust to excluding some countries from the analysis.

\section{Conclusions}

In the past decades, in addition to tobacco price policies, many countries introduced non-price tobacco control policies to reduce smoking. Empirical evidence on the effectiveness of such policies on smoking behavior is inconclusive in the sense that some studies find that tobacco control policies reduce smoking, while other studies find no effect. These differences in findings are partly due to differences in methodology. Many studies use a repeated cross-section type of approach with the incidence of smoking or the intensity of smoking as dependent variables. The effect of a tobacco control policy is analyzed by studying calendar time variation in these smoking variables. Sometimes, studies exploit crossregional or cross-state differences in the introduction of a tobacco control policy. If an effect is found on the incidence of smoking it is not clear whether this is caused by a decrease in the uptake of smoking or an increase in the quitting from smoking. If an effect is found on the intensity of smoking it is not always clear whether the incidence of smoking is affected as well. There are also a few studies that focus on the dynamics in smoking, studying the effects of tobacco control policies on the uptake of smoking sometimes in combination with the effect on the quitting from smoking.

Our paper contributes to the literature on the relationship between tobacco control policies and smoking initiation. We quantify non-price tobacco control policies using an index. Clearly, such an index has its limitations. Various components are calculated somewhat arbitrary, while the index does not include information about the enforcement of tobacco control policies. Nevertheless, such an index allows for cross-country comparisons and within-country calendar time variation.

We analyze the effects of tobacco control policies on the age of onset of smoking in eleven European countries which implemented different tobacco control policies in different years. We analyze the overall impact of tobacco control policies and study the separate components of these policies, i.e., smoke-free air laws, bans on advertising promotion and sponsorship, health warnings on tobacco product packaging and stop smoking treatment policies. In our empirical analysis, we use mixed proportional hazard rate models to control for observed as well as unobserved factors that can affect smoking initiation. Our model allows a tobacco control policy which is introduced in a particular calendar year to influence the starting rate of smoking through a shift in the smoking initiation rate. The smoking initiation rate is allowed to be country-specific, while we allow for crosscountry differences in birth-year trends.

We find that the starting rate of smoking decreases with educational attainment, is age-specific and for males we find that it decreases with tobacco prices. Our main result is that non-price tobacco control policies have no significant effect on the age of onset of smoking, neither for males nor for females. Current tobacco control policies do not seem to discourage young individuals from starting to smoke. The reason for this is not clear. It could be that young non-smokers do not agree with the implemented policies and, therefore, do not adjust their behavior. Our main findings do not imply that current tobacco control policies are all together ineffective in reducing smoking, since they could have reduced the intensity of smoking or stimulated the quit rate from smoking. Nevertheless, our main findings are alarming, because preventing young people from starting to smoke should be as important as trying to reduce their consumption or trying to convince them to quit once they have started. Even postponing smoking initiation to a later age would be helpful as later tobacco initiation will reduce smoking dependence. It is hard to suggest which type of tobacco control policy will successfully reduce smoking initiation. Clearly, youngsters need to be influenced in their decision making at a relatively young age.

Acknowledgements The authors thank participants of a Health Economics seminar at Erasmus School of Economics and two anonymous referees for useful comments and suggestions.

Open Access This article is distributed under the terms of the Creative Commons Attribution 4.0 International License (http://creativeco mmons.org/licenses/by/4.0/), which permits unrestricted use, distribution, and reproduction in any medium, provided you give appropriate credit to the original author(s) and the source, provide a link to the Creative Commons license, and indicate if changes were made.

\section{Appendix A: Details on our data}

\author{
Definition of variables:
}

- Education: Measured in terms of age when the respondent left formal education: No education/still studying, up to 15 , up to 20 , older than 20. 
- Cohort effect (age): Age of the respondent in the survey year to capture the cohort effects.

- Urbanization dummies: Rural town/village, small/mid town, large town.

The table below provides descriptives.

\begin{tabular}{lllllllll}
\hline & \multicolumn{3}{l}{ Females } & & \multicolumn{3}{l}{ Males } \\
\cline { 2 - 5 } \cline { 6 - 8 } & Mean & Min & Max & Mean & Min & Max \\
\hline Birth year-1900 & 81.4 & 69 & 99 & 82.1 & 69 & 99 \\
Education dummies & & & & & & \\
1. No education/still study- & 0.17 & 0 & 1 & 0.19 & 0 & 1 \\
ing & & & & & & \\
2. Up to 15 & 0.07 & 0 & 1 & 0.06 & 0 & 1 \\
3. Up to 20 & 0.38 & 0 & 1 & 0.37 & 0 & 1 \\
4. Older than 20 & 0.38 & 0 & 1 & 0.38 & 0 & 1 \\
Urbanization dummies & & & & & & \\
Rural town/village & 0.26 & 0 & 1 & 0.25 & 0 & 1 \\
Small/mid town & 0.44 & 0 & 1 & 0.43 & 0 & 1 \\
Large town & 0.30 & 0 & 1 & 0.32 & 0 & 1 \\
Austria & 0.12 & 0 & 1 & 0.09 & 0 & 1 \\
Germany & 0.13 & 0 & 1 & 0.13 & 0 & 1 \\
Finland & 0.07 & 0 & 1 & 0.07 & 0 & 1 \\
France & 0.08 & 0 & 1 & 0.08 & 0 & 1 \\
Ireland & 0.11 & 0 & 1 & 0.09 & 0 & 1 \\
Italy & 0.09 & 0 & 1 & 0.10 & 0 & 1 \\
Netherlands & 0.07 & 0 & 1 & 0.07 & 0 & 1 \\
Portugal & 0.10 & 0 & 1 & 0.08 & 0 & 1 \\
Spain & 0.09 & 0 & 1 & 0.09 & 0 & 1 \\
Sweden & 0.05 & 0 & 1 & 0.11 & 0 & 1 \\
United Kingdom & 0.08 & 0 & 1 & 0.09 & 0 & 1 \\
\hline
\end{tabular}

Based on 2065 males and 2442 females

\section{Appendix B: The tobacco control policy index}

\begin{tabular}{|c|c|c|c|}
\hline & & Max points & Rebased \\
\hline 1 & Smoke-free air & 22 & 40 \\
\hline A. & Cafes and restaurants & 8 & 14.6 \\
\hline B. & Public transport & 2 & 3.6 \\
\hline C. & Other public places & 2 & 3.6 \\
\hline D. & $\begin{array}{l}\text { Workplaces excluding cafes and } \\
\text { restaurants }\end{array}$ & 10 & 18.2 \\
\hline 2 & $\begin{array}{l}\text { Comprehensive bans on advertis- } \\
\text { ing and promotion }\end{array}$ & 13 & 23.6 \\
\hline A. & $\begin{array}{l}\text { Complete ban on tobacco advertis- } \\
\text { ing on television }\end{array}$ & 3 & 5.4 \\
\hline B. & $\begin{array}{l}\text { Complete ban on outdoor advertis- } \\
\text { ing (e.g. posters) }\end{array}$ & 2 & 3.6 \\
\hline
\end{tabular}

\begin{tabular}{|c|c|c|c|}
\hline & & Max points & Rebased \\
\hline C. & $\begin{array}{l}\text { Complete ban on advertising in } \\
\text { print media (e.g. newspapers and } \\
\text { magazines) }\end{array}$ & 2 & 3.6 \\
\hline D. & $\begin{array}{l}\text { Complete ban on indirect adver- } \\
\text { tising (e.g. cigarette branded } \\
\text { clothes, etc) }\end{array}$ & 2 & 3.6 \\
\hline E. & Ban on point of sale advertising & 1 & 1.8 \\
\hline F. & Ban on cinema advertising & 1 & 1.8 \\
\hline G. & Ban on sponsorship & 1 & 1.8 \\
\hline H. & Ban on internet advertising & 0.5 & 0.9 \\
\hline I. & Ban on radio advertising & 0.5 & 0.9 \\
\hline 3 & Large direct health warning labels & 10 & 18.2 \\
\hline A. & Rotating health warnings & 2 & 3.6 \\
\hline B. & Size of warning & 4 & 7.3 \\
\hline $\mathrm{C}$. & $\begin{array}{l}\text { Contrasting color (e.g. black letter- } \\
\text { ing on white background) }\end{array}$ & 1 & 1.8 \\
\hline D. & A picture or graphic image & 3 & 5.5 \\
\hline 4 & $\begin{array}{l}\text { Treatment to help dependent } \\
\text { smokers stop }\end{array}$ & 10 & 18.2 \\
\hline A. & Quit-line & 2 & 3.6 \\
\hline B. & $\begin{array}{l}\text { Network of smoking cessation } \\
\text { support and reimbursement of } \\
\text { treatment }\end{array}$ & 6 & 10.9 \\
\hline \multirow[t]{2}{*}{ C. } & Reimbursement of medications & 2 & 3.6 \\
\hline & Total score & 55 & 100 \\
\hline
\end{tabular}

Source: Nguyen et al. [34]

\section{References}

1. Abbring, J.H.: Stayers versus defecting movers: a note on the identification of defective duration models. Econ. Lett. 74, 327-331 (2002)

2. Adda, J., Cornaglia, F.: The effect of bans and taxes on passive smoking. Am. Econ. J. Appl. Econ. 2(1), 1-32 (2010)

3. Anger, S., Kvasnicka, M., Siedler, T.: One last puff? Public smoking bans and smoking behavior. J. Health Econ. 30(3), 591-601 (2011)

4. Blecher, E.: The impact of tobacco advertising bans on consumption in developing countries. J. Health Econ. 27(4), 930-942 (2008)

5. Boes, S., Marti, J., Maclean, J.C.: The impact of smoking bans on smoking and consumer behavior: quasi-experimental evidence from Switzerland. Health Econ. 24(11), 1502-1516 (2015)

6. Bosdriesz, J.R., Willemsen, M.C., Stronks, K., Kunst, A.E.: Tobacco control policy and socio-economic inequalities in smoking in 27 European countries. Drug Alcohol Depend. 165, 79-86 (2016)

7. Cawley, J., Markowitz, S., Tauras, J.: Lighting up and slimming down: the effects of body weight and cigarette prices on adolescent smoking initiation. J. Health Econ. 23(2), 293-311 (2004)

8. Chaloupka, F., Grossman, M.: Price, tobacco control policies and youth smoking. National Bureau of Economic Research. In: Working Paper No 5740 (1996)

9. Chaloupka, F., Warner, K.: The economics of smoking. In: Culyer, A.J., Newhouse, J.P. (eds.) Handbook of Health Economics, vol. 1, pp. 1539-1627. Elsevier, New York (2000). (Chapter 29) 
10. Chaloupka, F., Wechsler, H.: Price, tobacco control policies and smoking among young adults. J. Health Econ. 16(3), 359-373 (1997)

11. Cotti, C., Nesson, E., Tefft, N.: The effects of tobacco control policies on tobacco products, tar, and nicotine purchases among adults: evidence from household panel data. Am. Econ. J. Econ. Policy 8(4), 103-123 (2016)

12. Darden, M.: Smoking, expectations, and health: a dynamic stochastic model of lifetime smoking behavior. J. Polit. Econ. 125(5), 1465-1522 (2017)

13. DeCicca, P., Kenkel, D., Mathios, A.: Putting out the fires: Will higher taxes reduce the onset of youth smoking? J. Polit. Econ. 110(1), 144-169 (2002)

14. DeCicca, P., Kenkel, D., Mathios, A.: Cigarette taxes and the transition from youth to adult smoking: smoking initiation, cesation, and participation. J. Health Econ. 27(4), 904-917 (2008)

15. Del Bono, E., Vuri, D.: Smoking behaviour and individual wellbeing: a fresh look at the effects of the 2005 public smoking ban in Italy. Oxford Econ. Pap. 70(3), 741-762 (2018)

16. Douglas, S.: The duration of the smoking habit. Econ. Inq. 36, 49-64 (1998)

17. Douglas, S., Hariharan, G.: The hazard of starting smoking: estimates from a split population duration model. J. Health Econ. 13, 213-230 (1994)

18. Forster, M., Jones, A.: The role of tobacco taxes in starting and quitting smoking: duration analysis of British data. J. R. Stat. Soc. A 164, 517-547 (2001)

19. Glied, S.: Youth tobacco control: reconciling theory and empirical evidence. J. Health Econ. 21(1), 117-135 (2002)

20. Guindon, G.E.: The impact of tobacco prices on smoking onset in Vietnam: duration analyses of retrospective data. Eur. J. Health Econ. 15(1), 19-39 (2014)

21. Jones, A., Laporte, A., Rice, N., Zucchelli, E.: Do public smoking bans have an impact on active smoking? Evidence from the UK. Health Econ. 24, 175-192 (2015)

22. Joossens, L., Raw, M.: Tobacco control scale: a new scale to measure country activity. Tob. Control 15, 247-253 (2006)

23. Kidd, M., Hopkins, S.: The hazard of starting and quitting smoking: some Australian evidence. Econ. Record 80, 177-192 (2004)

24. Levine, P.B., Gustafson, T.A., Velenchik, A.D.: More bad news for smokers? The effects of cigarette smoking on wages. Ind. Labor Relat. Rev. 50(3), 493-509 (1997)

25. Lillard, D., Molloy, E., Sfekas, A.: Smoking initiation and the iron law of demand. J. Health Econ. 32(1), 114-127 (2013)

26. Lillard, D.R., Önder, Z.: Health information and life-course smoking behavior: evidence from Turkey. Eur. J. Health Econ. 20(1), 149-162 (2019)

27. López Nicolás, A.: How important are tobacco prices in the propensity to start and quit smoking? An analysis of smoking histories from the Spanish National Health Survey. Health Econ. 11, 521-535 (2002)

28. Marti, J.: The impact of tobacco control expenditures on smoking initiation and cessation. Health Econ. 23, 1397-1410 (2014)

29. Mathers, C., Stevens, G., Tursan, E., Wolfenden, L.: Mortality Attributable to Tobacco. World Health Organization, Geneva (2012)

30. Meier, A.N., Odermatt, R., Stutzer, A.: Tobacco sales prohibition and teen smoking. IZA Discussion Paper No. 12231 (2019)
31. Meier, K., Licari, M.: The effect of cigarette taxes on cigarette consumption, 1955 through 1994. Am. J. Pub. Health 87(7), 1126-1130 (1997)

32. Nagelhout, G., de Vries, H., Boudreau, C., Allwright, S., McNeill, A., van den Putte, B., Fong, G., Willemsen, M.: Comparative impact of smoke-free legislation on smoking cessation in three European countries. Eur. J. Pub. Health 1(22 Supplement), 4-9 (2012)

33. Nagelhout, G., Willemsen, M., de Vries, H.: The population impact of smoke-free work and hospitality industry legislation on smoking behaviour. Findings from a national population survey. Addiction 106, 816-823 (2011)

34. Nguyen, L., Rosenqvist, G., Pekurinen, M.: Demand for Tobacco in Europe an Econometric Analysis of 11 Countries for the PPACTE Project. National Institute for Health and Welfare, Helsinki (2012)

35. Nonnemaker, J.M., Farrelly, M.C.: Smoking initiation among youth: the role of cigarette excise taes and prices by race/ethnicity and gender. J. Health Econ. 30, 560-567 (2011)

36. Odermatt, R., Stutzer, A.: Smoking bans, cigarette prices and life satisfaction. J. Health Econ. 44, 176-194 (2015)

37. Orphanides, A., Zervos, D.: Rational addiction with learning and regret. J. Polit. Econ. 103(4), 739-758 (1995)

38. Pirie, K., Peto, R., Reeves, G.K., Green, J., Beral, V.: The 21st century hazard of smoking and benefits of stopping: a prospective study of one millon women in the UK. The Lancet 381, 133-141 (2013)

39. Powell, L.M., Tauras, J.A., Ross, H.: The importance of peer effects, cigarette prices and tobacco control policies for youth smoking behavior. J. Health Econ. 24(5), 950-968 (2005)

40. Saffer, H., Chaloupka, F.: The effect of tobacco advertising bans on tobacco consumption. J. Health Econ. 19(6), 1117-1137 (2000)

41. Sharapova, S., Reyes-Guzman, C., Singh, T., Phillips, E., Marynak, K.L., Agaku, I.: Age of tobacco use initiation and association with current use and nicotine dependence among US middle and high school students, 2014-2016. Tob. Control (2018). https ://doi.org/10.1136/tobaccocontrol-2018-054593

42. Suranovic, S.M., Goldfarb, R.S., Leonard, T.C.: An economic theory of cigarette addiction. J. Health Econ. 18(1), 1-29 (1999)

43. Van Ours, J.C.: Dynamics in the use of drugs. Health Econ. 15(12), 1283-1294 (2006)

44. Villar, J.G., Nicolás, Á.L.: Who is afraid of smoking bans? An evaluation of the effects of the Spanish clean air law on expenditure at hospitality venues. Eur. J. Health Econ. 16(8), 813-834 (2015)

45. Warner, K.: Selling Smoke: Cigarette Advertising and Public Health. American Public Health Association, Washington (1986)

46. WHO: Report on the Global Tobacco Epidemic. World Health Organization, Geneva (2013)

47. Wilson, L.M., Tang, E.A., Chander, G., Hutton, H.E., Odelola, O.A., Elf, J.L., Heckman-Stoddard, B.M., Bass, E.B., Little, E.A., Haberl, E.B., Apelberg, B.J.: Impact of tobacco control interventions on smoking initiation, cessation, and prevalence: a systematic review. J. Environ. Pub. Health 2012, 1-36 (2012)

Publisher's Note Springer Nature remains neutral with regard to jurisdictional claims in published maps and institutional affiliations. 